\title{
Patterns of epidemiology and control of onchocerciasis in West Africa
}

\author{
B. Boatin ${ }^{1}$, D.H. Molyneux ${ }^{2 *}$, J.M. Hougard ${ }^{1}$, O.W. Christensen ${ }^{3}$, \\ E.S. Alley ${ }^{1}$, L. Yameogo ${ }^{1}$, A. Seketeli ${ }^{1}$ and K.Y. Dadzie ${ }^{1}$ \\ ${ }^{1}$ World Health Organization, Onchocerciasis Control Programme, BP 549, \\ Ouagadougou, Burkina Faso: ${ }^{2}$ Liverpool School of Tropical Medicine, \\ Pembroke Place, Liverpool, L3 5QA, UK: ${ }^{3}$ World Health Organization, \\ OCP Liaison Office, 1211 Geneva 27, Switzerland
}

\begin{abstract}
This paper summarizes the work of the Onchocerciasis Control Programme (OCP) in West Africa, a programme which over a 22 year history has reduced the public health problems of blinding onchocerciasis in eleven countries of West Africa through vector control and, more recently, ivermectin distribution. The paper emphasizes the different approaches to control the programme has developed in the different parts of the programme area which have been determined by the epidemiology of the disease (savanna/forest form), the migratory characteristics of the vectors, intensity of the disease before commencement of treatment, the combined impact of vector control and ivermectin and the likelihood of infiltration of infective blackflies from outside the programme area. The programme has constantly monitored the impact of operations on the trends in prevalence, incidence, annual transmission potential, ocular morbidity and species of fly populations, and as a result, has identified areas where special interventions are required until the programme comes to an end in 2002. The paper illustrates the changes in intensity of infection as measured by community microfilarial load and annual transmission potential over the duration of the programme control activities. The paper also defines and justifies the control strategies in different areas and identifies areas for special interventions.
\end{abstract}

\section{Introduction}

Onchocerciasis (river blindness) is a disease caused by a filarial nematode parasite, Onchocerca volvulus, transmitted by blackflies (Simulium species). There are approximately 17.5 million people infected and of these it is estimated there are some 270,000 blind (in 26 countries in Africa; Yemen and six in the Americas) (WHO, 1995). Different patterns of epidemiology exist and the stratification of the disease is shown in table 1 . Such patterns are associated with different strains of the parasite (forest v. savanna) (Duke et al., 1966; Zimmerman et al., 1992) and different vectors (cytospecies or species) (Crosskey, 1987; WHO, 1995), the abundance of the vectors and degree of anthropophily, their vectorial and migratory capacity (Le Berre et al., 1990; WHO, 1995).

*Author for correspondence.
The parasite lives as adults (males and females) in subcutaneous nodules. The females, when fertilized, produce millions of microfilaria (embryos) about 250-300 $\mu \mathrm{m}$ in length which live predominantly in the skin but migrate throughout the intercellular fluid and reach the eye leading to the characteristic ocular symptoms which lead to blindness. In addition, the presence of microfilariae in the skin causes intense itching, thickening and depigmentation of the skin and loss of elasticity whilst other clinical manifestations such as hanging groin and elephantiasis of the genitals also occur (see WHO, 1995).

\section{Approaches to control}

The Onchocerciasis Control Programme (OCP) conceived in 1969 and launched in 1974 had as its objective to eliminate onchocerciasis as a disease of public health 
Table 1. Stratification of global onchocerciasis epidemiology and control.

\begin{tabular}{|c|c|c|c|c|}
\hline Geographical locality & Epidemiological & Operational & Disease management & Prevention \\
\hline $\begin{array}{l}\text { Africa } \\
\text { South of Sahara. } \\
\text { Onchocerciasis Control } \\
\text { Programme (OCP) } \\
\text { countries. } \\
\text { 1. Original areas - Benin, } \\
\text { Burkina Faso, Cote } \\
\text { d'Ivoire, Ghana, Mali, } \\
\text { Niger, Togo. } \\
\text { 2. Extension areas. } \\
\text { Southern areas of Ghana, } \\
\text { Togo, Benin; western } \\
\text { extension, Guinea, Guinea } \\
\text { Bissau, Sierra Leone, } \\
\text { Senegal. } \\
\text { Non-OCP countries } \\
\text { 3. Nigeria to Sudan. } \\
\text { 4. West and Equatorial } \\
\text { Africa, Guinea-Bissau to } \\
\text { Gabon. Rain forest. } \\
\text { 5. Zaire Basin. }\end{array}$ & $\begin{array}{l}\text { Savannah woodland of } \\
\text { northern tropics. Hyper- } \\
\text { endemic villages close to } \\
\text { rivers. Historically } \\
\text { associated with high } \\
\text { blindness rate; resulting } \\
\text { in depopulation. } \\
\text { Major vectors in savanna } \\
\text { S. damnosum and } S \text {. } \\
\text { sirbanum. Annual } \\
\text { transmission potential or } \\
\text { more than } 100 \text { associated } \\
\text { with blindness risk. } \\
\text { Highly migratory. } \\
\text { In forest areas less } \\
\text { blinding form of O. } \\
\text { volvulus transmitted by } \\
\text { forest vectors } S \text {. soubrense, } \\
\text { S. yahense, } S \text {. sanctipauli, } S \text {. } \\
\text { squamosum, S. leonense }\end{array}$ & $\begin{array}{l}\text { 1. Vector control by } \\
\text { weekly aerial larviciding } \\
\text { for } 14 \text { years eliminates } \\
\text { adult worms in human } \\
\text { reservoir. Ivermectin for } \\
\text { recrudescence or } \\
\text { undetected foci. } \\
2 \text {. Combined vector } \\
\text { control and ivermectin for } \\
12 \text { years projected to } \\
\text { reduce disease to non- } \\
\text { significant level. } \\
\text { Ivermectin alone in areas } \\
\text { of low CMFL (<10) where } \\
\text { no invasion of } \\
\text { Simulium threatens } \\
\text { original OCP area. } \\
3 / 4 / 5 \text {. Ivermectin through } \\
\text { community based } \\
\text { distribution systems. } \\
6 . \text { or } 3-5 \text {. Focal vector } \\
\text { control could achieve }\end{array}$ & $\begin{array}{l}\text { 1. Vector control applied } \\
\text { due to lack of availability } \\
\text { of drug for large scale } \\
\text { use till 1986. Thereafter } \\
\text { ivermectin to reduce } \\
\text { infection and prevent } \\
\text { development of ocular } \\
\text { lesions. } \\
\text { 2. Ivermectin throughout } \\
\text { for extended periods up } \\
\text { to } 20 \text { years as ivermectin } \\
\text { does not interrupt } \\
\text { transmission. } \\
3 \text {. Impact of ivermectin on } \\
\text { skin disease and other } \\
\text { manifestations of } O \text {. } \\
\text { volvulus infection to be } \\
\text { assessed. }\end{array}$ & $\begin{array}{l}\text { 1. Maintain surveillance } \\
\text { system for recrudescence } \\
\text { using tests for early } \\
\text { detection of transmission. } \\
\text { Institute ivermectin if } \\
\text { appropriate. Establish } \\
\text { appropriate surveillance } \\
\text { via integration in } \\
\text { public health systems. } \\
\text { Possible detection of early } \\
\text { transmission by detection } \\
\text { of infective larvae in } \\
\text { blackflies. } \\
\text { 2. Maintenance of } \\
\text { ivermectin distribution. } \\
\text { Ensure high coverage cost- } \\
\text { effectiveness and } \\
\text { sustainable delivery via } \\
\text { community assisted by } \\
\text { NGOs. Ivermectin } \\
\text { availability free of charge. }\end{array}$ \\
\hline
\end{tabular}

5. Zaire Basin. Ethiopia to Southern Malawi. squamosum, $S$. leonense control could achieve (Sierra Leone) which are eradication of S. damnosum less efficient and non or or S. neavei. less migratory.

\section{Central America}

Guatemala; Mexico in well defined foci. Cross border movement of migrant workers may spread the disease.

Anthropophilic $S$. ochraceum in highland foci; S. metallicum more zoophilicalso involved. Inefficiencyas vector due to buccal armature complicated by abundance.

\section{South America}

1. Brazil, S. Venezuela.

2. N. Venezuela.

3. Ecuador, Colombia.

1. Primary vectors. $S$. oyapockense and $S$. guianense.

2. Primary vector $S$. metallicum.

3. Primary vector $S$

exiguum.

1,2 . Secondary vector $S$. exiguum.

\section{Control by ivermectin Ivermectin based. distribution via national As 2 above but unlikely
to make major impact.} programmes through twice yearly distribution.
Vector control not feasible. Ivermectin based. Integration of ivermectin with other programmes.
As 2 above but unlikely to make major impact.

Yemen

Distributed along wadis. A member of the $S$.

damnosum complex.

and socio-economic importance' in seven countries (Benin, Burkina Faso, Cote d'Ivoire, Ghana, Mali, Niger and Togo) of West Africa. In 1986, the programme began operations in an additional four countries in the West (Guinea, Guinea Bissau, Senegal and Sierra Leone) and extended operations into the South and South-east in Benin, Ghana and Togo. The rationale for these extensions related to findings that Simulium were able to migrate and hence re-invade controlled areas over several hundred kilometres (Garms et al., 1979)

The control strategy of the OCP was based on weekly aerial larviciding of all breeding sites in the rivers of the programme area using the organophosphate temephos (Abate), an insecticide with limited toxicity to non-target aquatic fauna. Larviciding would prevent emergence of any adult flies and hence eliminate transmission of the parasite (O. volvulus). It was proposed that aerial larviciding should be continued for a period initially estimated at 20 years which was the maximum duration of life of the adult worm. Recent detailed investigations based on field studies and supported by model predictions suggest a reproductive life span of adult worms of 9-12 years (Habbema et al., 1992). Transmission of third-stage larvae (L3) to humans with the resultant cessation of 


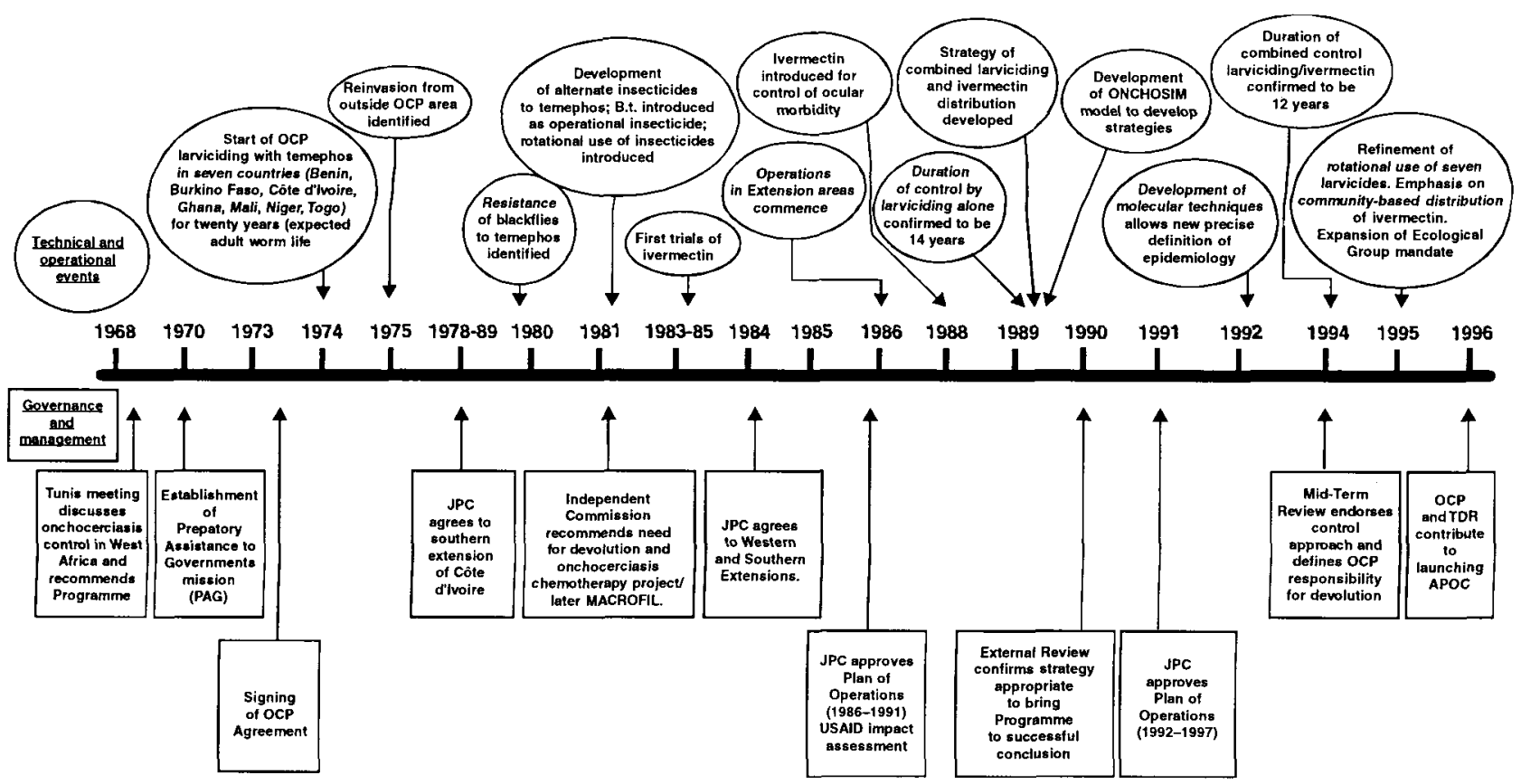

Fig. 1. History and evolution of control strategy development in the Onchocerciasis Control Programme.

recruitment of adults into the human population occurred when larviciding commenced. In the absence of a nontoxic drug which could be used on a wide scale which would kill the adult worm, transmission control was the only strategy to deal with such an extensive public health problem which had become a major impediment to development. The OCP has evolved rapidly both managerially and technically over the last 22 years (Samba, 1994). The changes which have taken place are outlined in fig. 1 which emphasizes the evolution of the OCP in response to both technical needs, scientific advances and participating and donor country policies. These changes and the effects of control have resulted in a situation of enhanced complexity, both in terms of epidemiology on the one hand and control strategy on the other, respecting the need to bring the OCP to a successful conclusion to safeguard public health achievements and ensure their sustainability. This need in 1990 led to the expansion of the Programme Objective to incorporate the statement 'to ensure the countries are in a position to maintain that achievement' referring to the need to devolve responsibility for post-OCP activities for onchocerciasis surveillance and control to appropriate national health systems. This has been facilitated by the widespread use of ivermectin (Mectizan ${ }^{\circledR}$ ) which became an integral part of OCP control strategy in the late 1980s (Webbe, 1992). At present in the OCP area some 3.5 million tablets are distributed annually to 2.5 million individuals. The advent of ivermectin based control has had a significant impact on control strategy through the generosity of the manufacturer, Merck and Co., in providing the drug free for the control of onchocerciasis. The OCP control strategy has evolved in response to key applied research findings. In addition, a continuous search for more cost-effective approaches to control in a programme which expends a high proportion of its costs on aerial larviciding (C. 65$70 \%$ of $\$ 17 \mathrm{~m}$ budget for 1998 ). The length of the river systems under control have been reduced from the peak of $50,000 \mathrm{~km}$ over an area of $1.2 \mathrm{~m} \mathrm{~km}^{2}$ in the mid $1980 \mathrm{~s}$ to a planned level in the last year of the 4th phase of the OCP in 1997 to $12,000 \mathrm{~km}$ in an area of $600,000 \mathrm{~km}^{2}$. The projected lengths of rivers treated in the final year of the programme will be $8000 \mathrm{~km}$ over an area of $400,000 \mathrm{~km}^{2}$.

The OCP has been subjected to extensive external review in order to reassure the donor community of the validity of the approaches to control (Webbe, 1992; Molyneux, 1995) whilst Samba (1994) has recorded the importance of the OCP's experience in the context of public health management issues. There have been in addition reviews of 10 years of onchocerciasis control (WHO, 1985) and a monograph (O-Now, Leiden 1990) which included many papers emanating from OCP activities and, recently the overview of 20 years of onchocerciasis control (WHO, 1997). The recent WHO Expert Committee Report (WHO, 1995) summarizes all aspects of onchocerciasis control on the basis not only of OCP experiences but on opportunities for ivermectin-based control outside OCP in Africa as well as South and Central American foci. The utilization of ivermectin as a tool to control onchocerciasis morbidity has resulted in the establishment of a new programme, the African Programme for Onchocerciasis Control (APOC). APOC seeks to establish sustainable community-directed ivermectin delivery systems in the non-OCP endemic countries of Africa (Remme, 1995). The programme is over a 12 year period through joint government and nongovernmental development organization (NGDO) partnerships which will operate in-country via national Onchocerciasis Task Forces; each community-directed treatment project will be designed to achieve sustainable delivery of ivermectin after 5 years programme support. 
Table 2. Epidemiological, entomological, ophthalmological and ivermectin distribution OCP performance indicators.

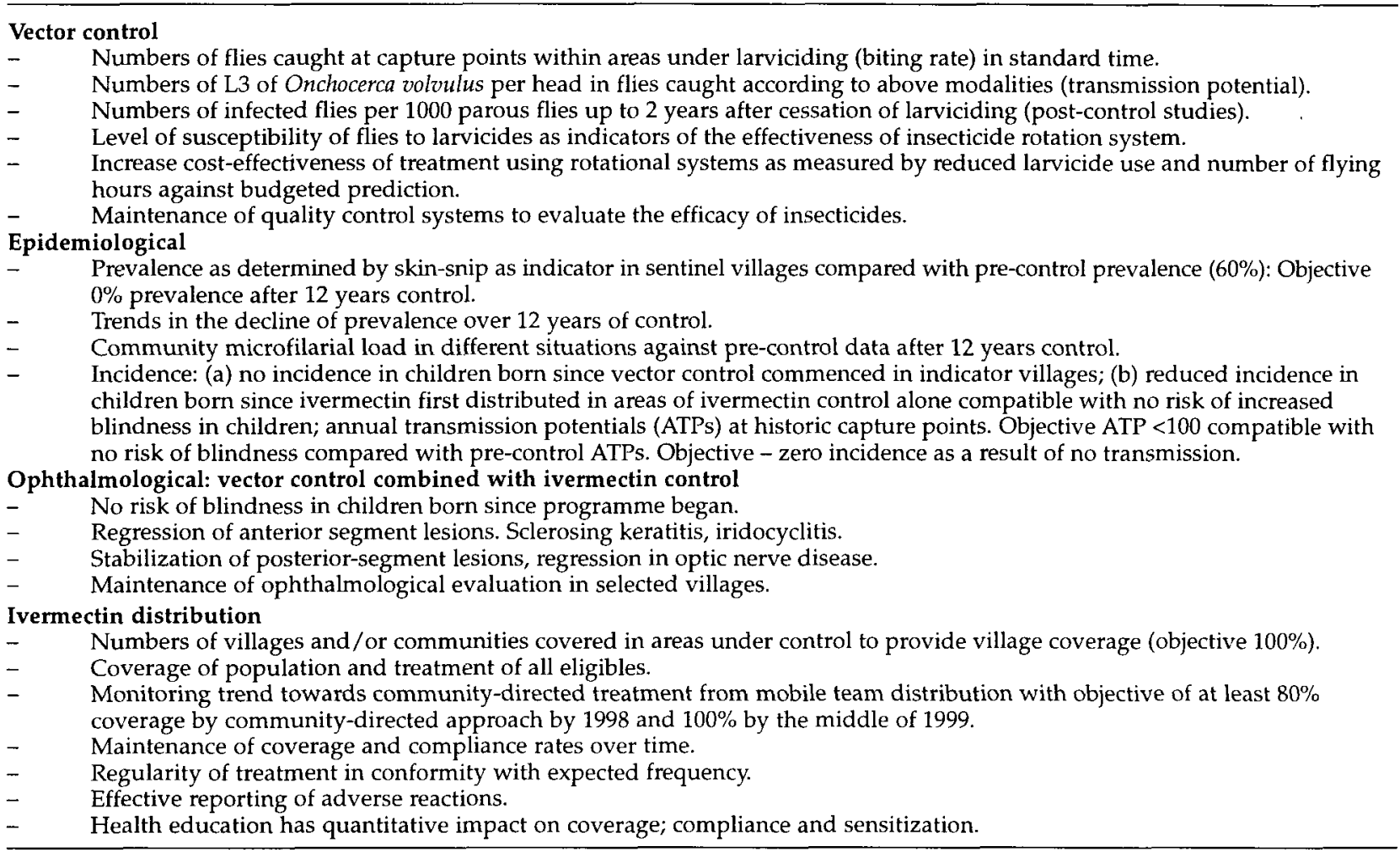

The OCP was established to control onchocerciasis in the West African savanna belt where the disease caused massive depopulation and migration from river valleys, prevented access to fertile alluvial river basins and in some villages caused up to $30 \%$ of adults in communities to be blind and unable to work, providing an increased burden on already impoverished rural communities. Whilst the effects of blindness can be quantified more easily in terms of social and economic consequences of the burden on the household, the impact of other symptoms such as itching are only recently being scrutinized. It is clear from initial results that there is an important psychosocial and economic dimension of onchocercal skin disease as yet unquantified (WHO, 1995) but which assumes much importance to afflicted individuals who feel and are stigmatized.

The OCP has consistently planned its activities on an annual basis and submitted detailed plans of operations for the various financial phases. The final phase of the operational plan (1998-2002) has been developed following a review of OCP activities (see Molyneux, 1995) and this included extensive discussions on trends in the prevalence, incidence, levels of community microfilarial load (CMFL), ophthalmological changes in the presence of control, annual transmission potentials (ATP) and numbers of infective L3/1000 parous females, proportion of $O$. volvulus v. O. ocheng $i \mathrm{~L} 3$ in fly populations indicating the degree of zoophily (animal feeding), and proximity to invading fly populations outside the boundaries of the control programme (e.g. Nigeria; south of OCP border).
Table 2 provides a list of indicators which determine the decisions to be made on approaches to control.

The different control situations and epidemiological characteristics are indicated in fig. 2 . The pre-control indicators of the annual transmission potential and prevalence of skin microfilaria throughout the programme area are compared with the current situation in figs $3 a \& b$ and $4 \mathrm{a} \& \mathrm{~b}$. The existing distribution of ivermectin is shown in fig 5 .

\section{Control strategy}

\section{Area 1: Western extension.}

\section{Senegal, western Mali, northern Guinea, Guinea Bissau}

In this area, morbidity control is by ivermectin delivery either annually or biannually. The rationale for only using ivermectin to control disease is that endemicity is low and although prevalence could be high, the intensity of infection as judged by CMFLs is low. Whilst transmission is by savanna blackflies, their migration does not pose any threat to the original OCP area. Annual transmission potential estimates were initially flawed as a result of high levels of zoophily in Simulium as the L3 were often $O$. ochengi (Trees, 1992). Molecular identification shows $60 \%$ of $\mathrm{L} 3$ are $O$. ochengi in S. sirbanum/S. damnosum. Blindness due to Onchocerca was a limited public health problem in a sparsely populated area. Recent epidemiological studies indicate that even in the absence of larviciding, an 


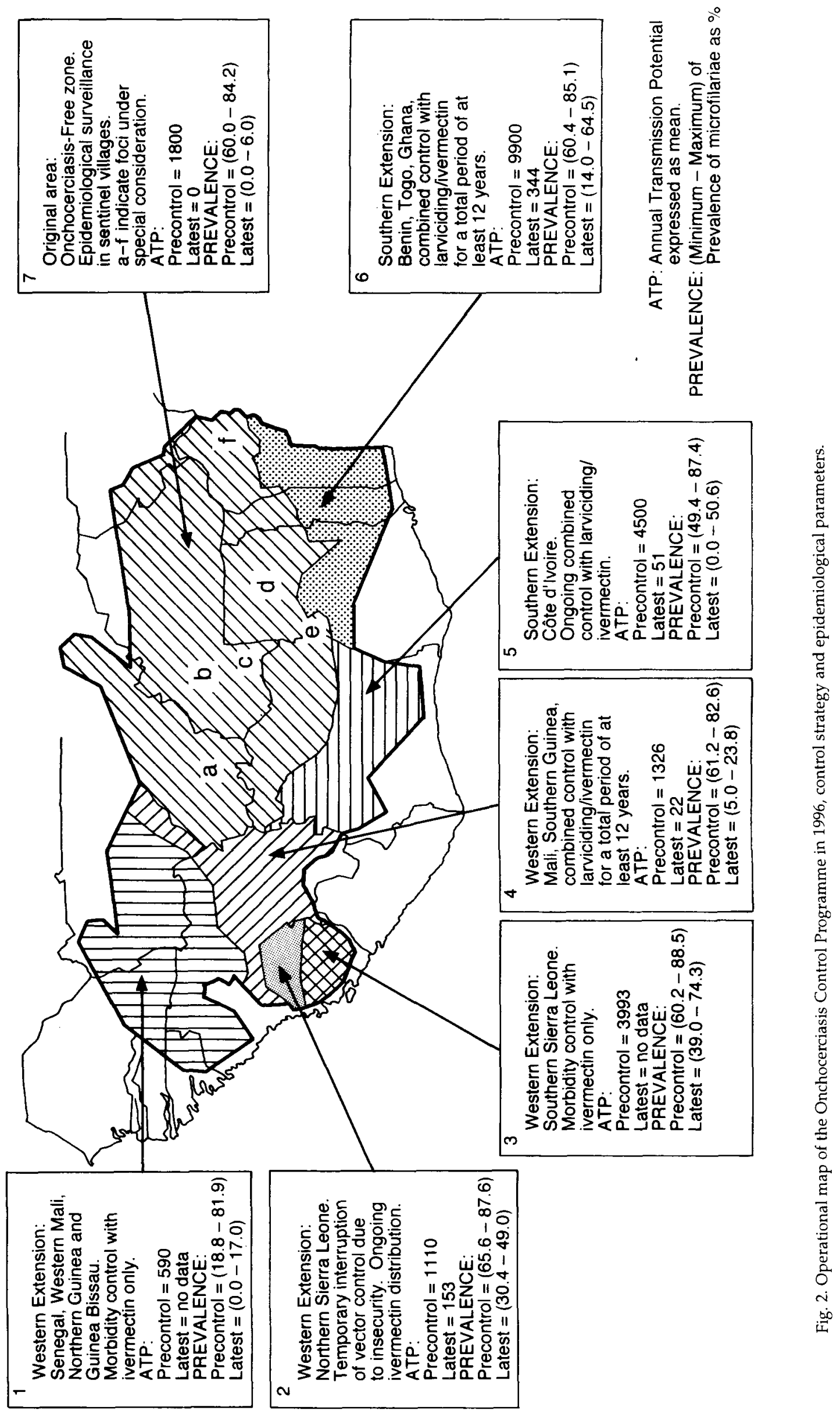




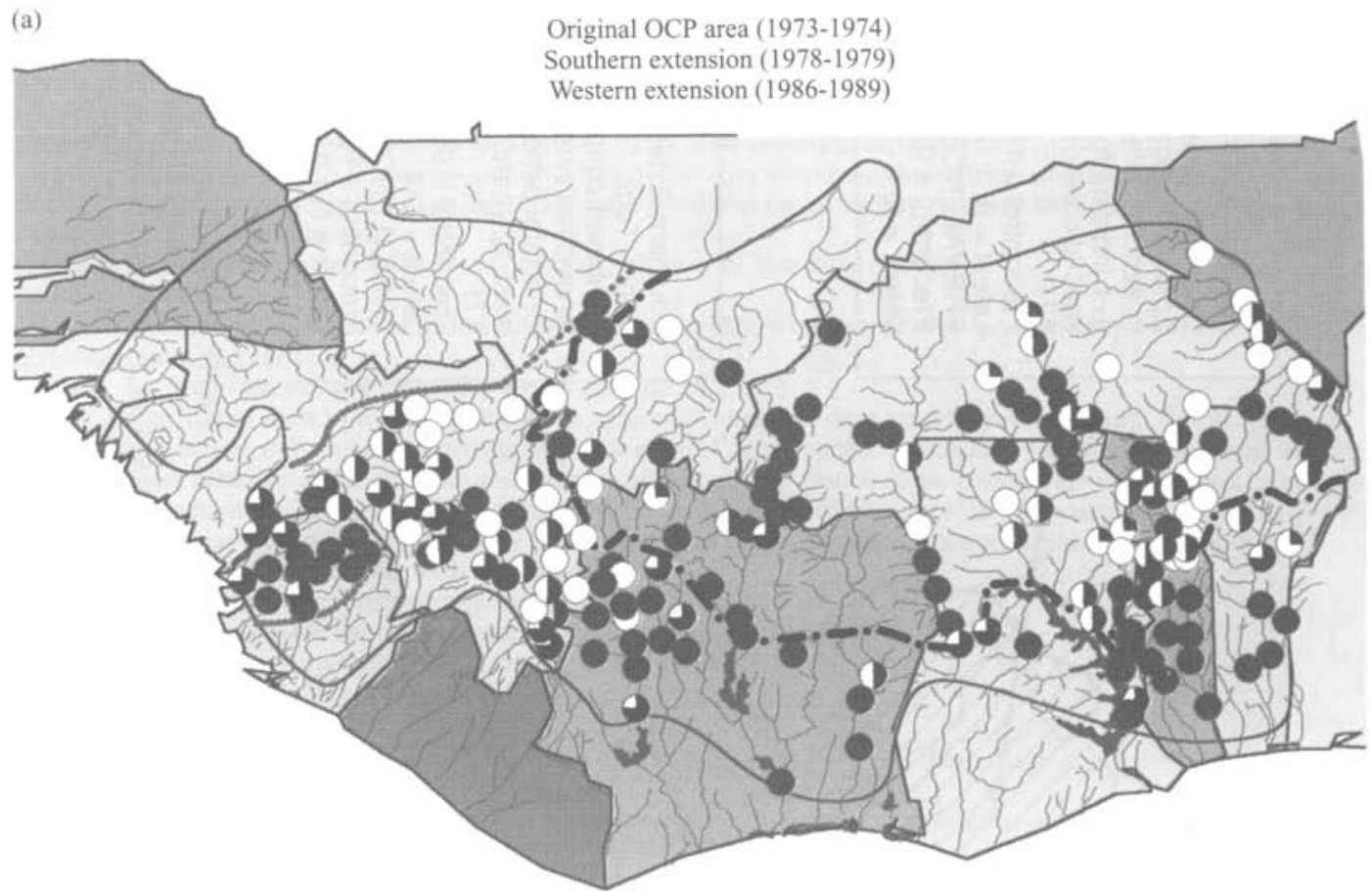

(b)

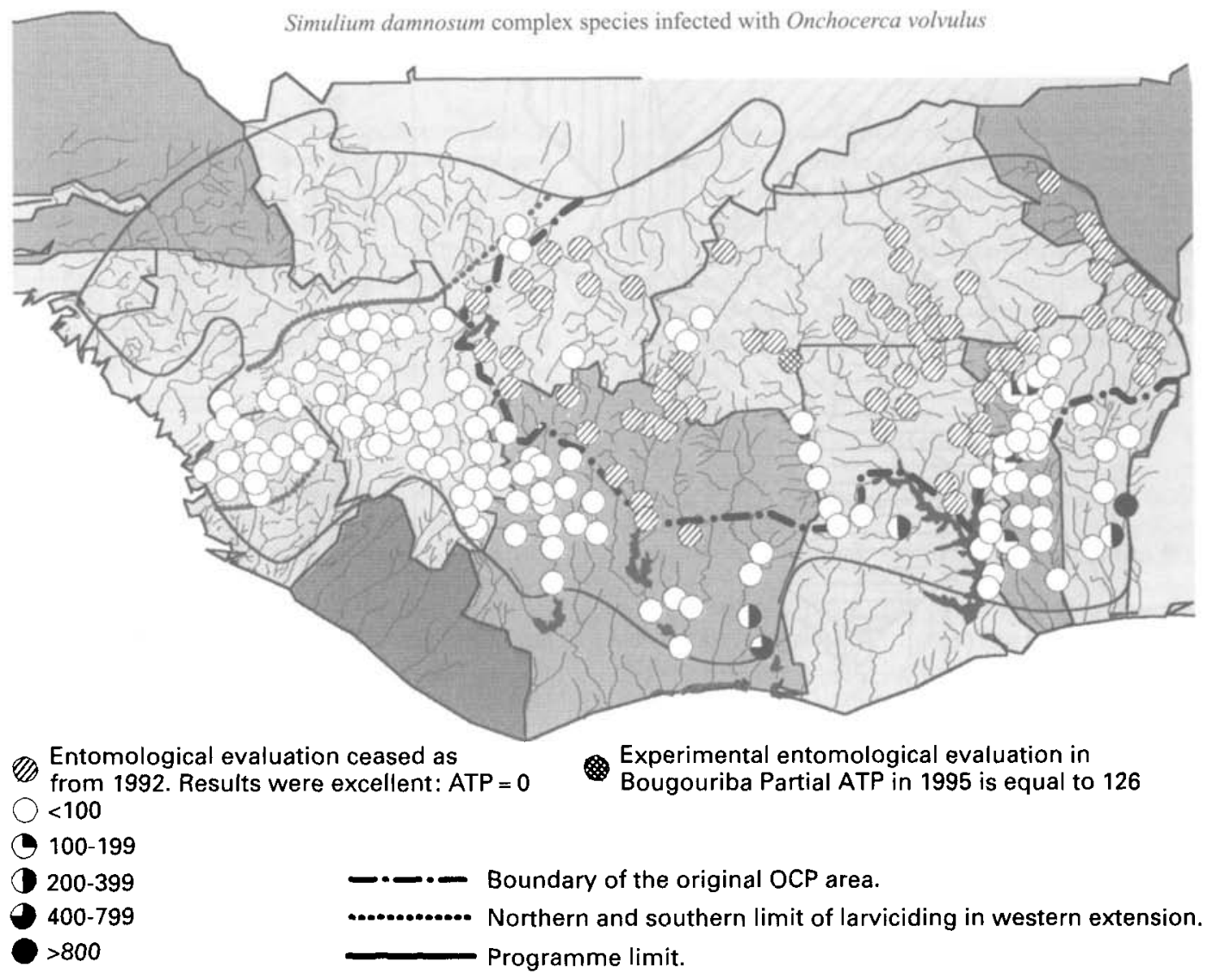

Fig. 3. Annual transmission potentials pre-control (a) and in 1995(b). 
(a)

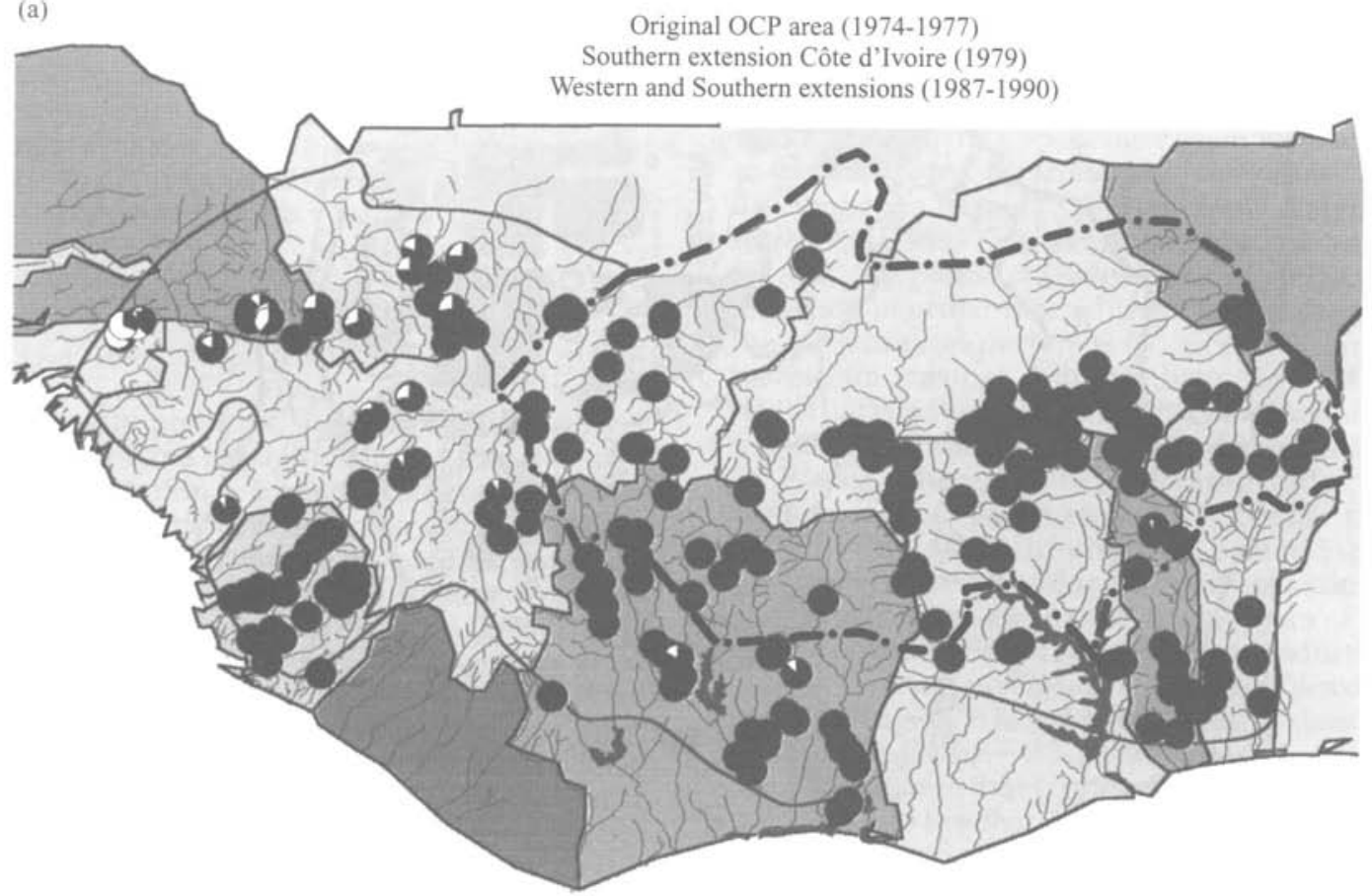

(b)

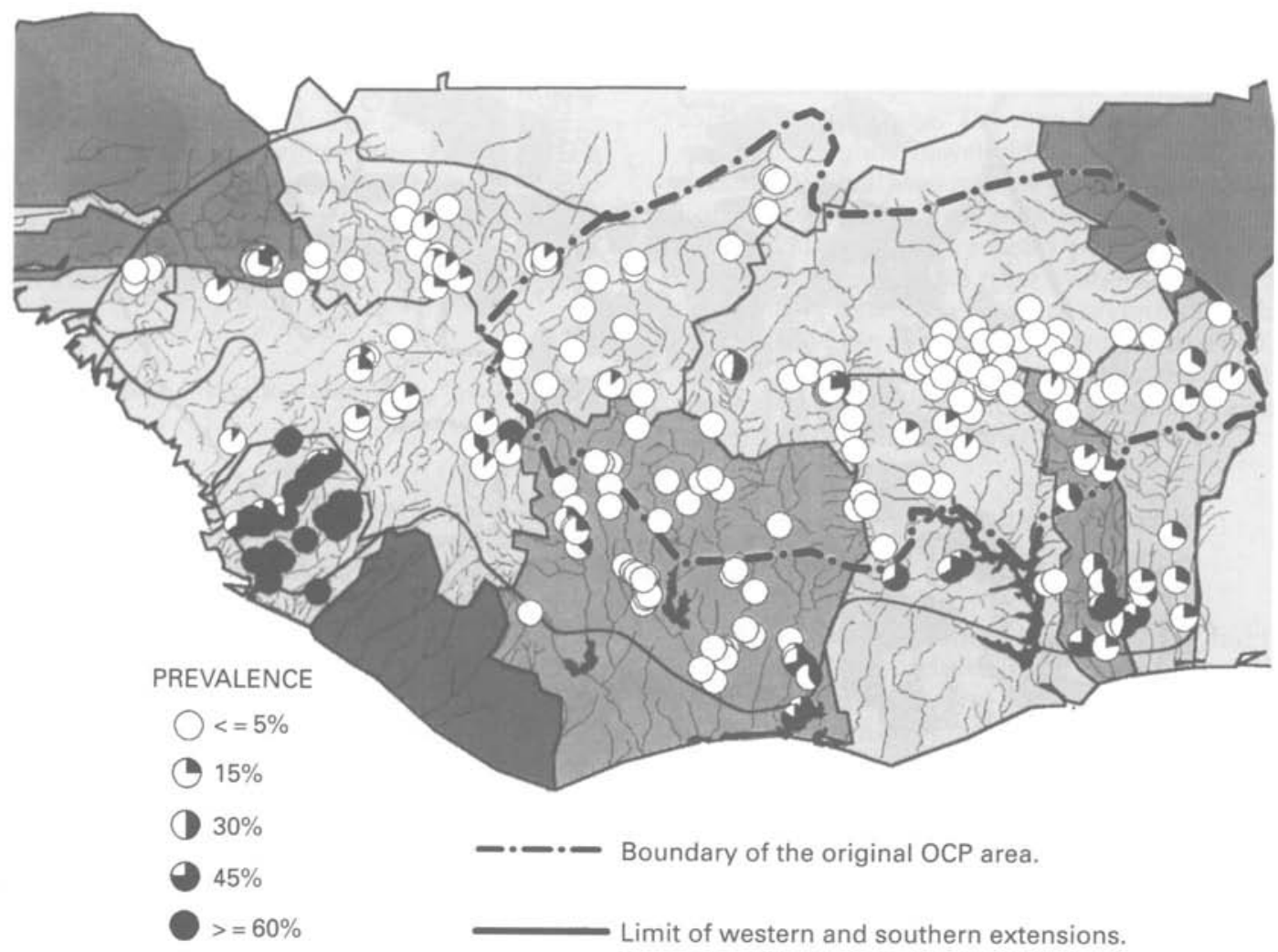

Fig. 4. Prevalence of skin microfilariae pre-control (a) and from 1993 to 1996(b). 


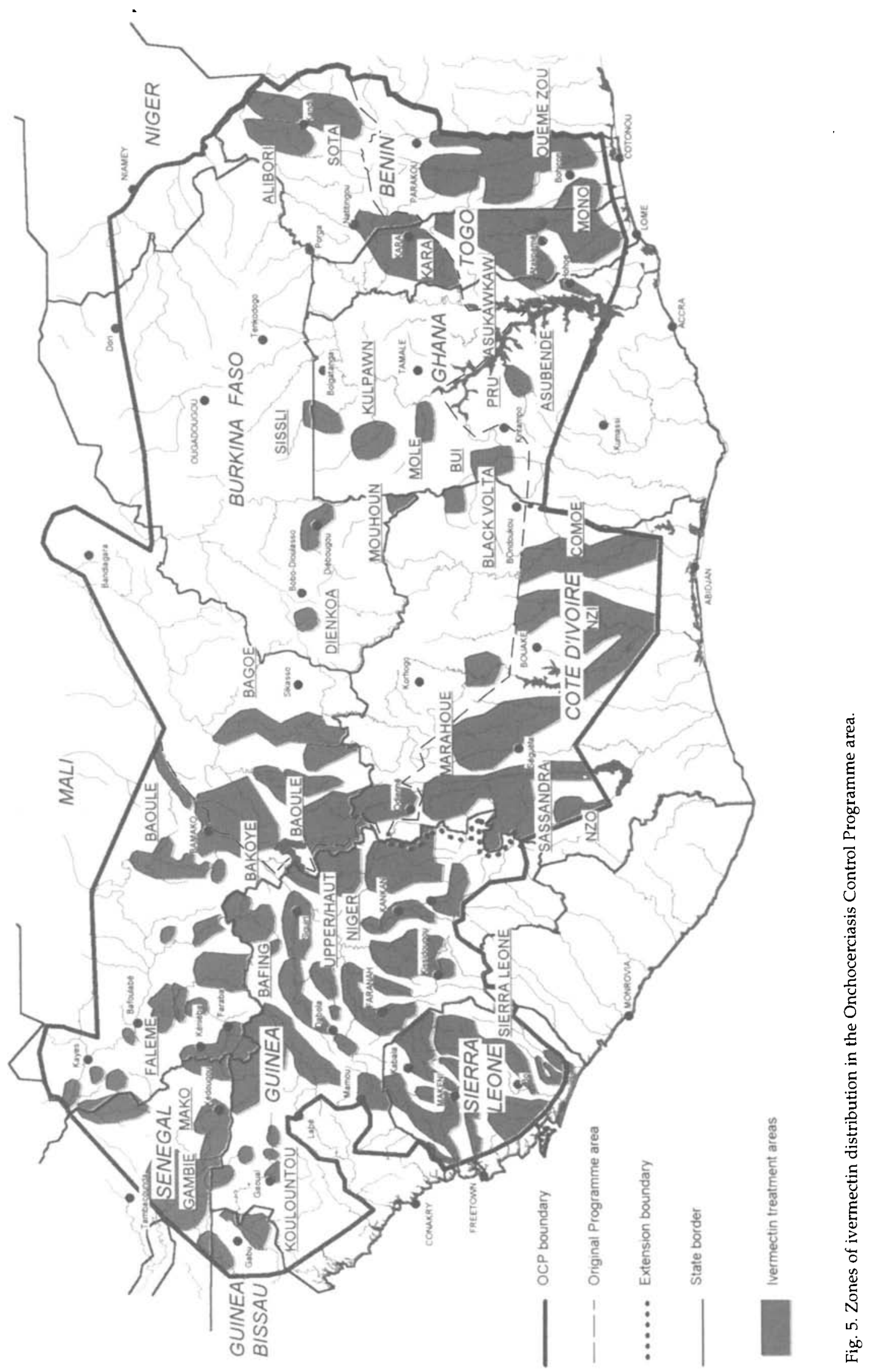


ivermectin-alone strategy providing high coverage has prevented any incidence of infection in the under-5 population who qualify to receive ivermectin for the first time. Recent studies in Guinea Bissau and Guinea show a reduction in prevalence of $16-23 \%$ to $0.2-3.2 \%$ and $48.2-$ $62.7 \%$ to $8.6-44.6 \%$ respectively, results similar to those observed in Senegal and North West Mali.

\section{Area 2: Western extension}

\section{Northern Sierra Leone}

Due to security problems, aerial larviciding of river systems Seli/Bagbe and Kaba/Mongo was suspended for 2-4 years from 1992-1996; ivermectin distribution was also suspended over the period but recommenced in early 1996. During 1995 it was found that the proportion of savanna flies was lower than originally found in these rivers but this rose significantly between 1995 and 1996; it was considered that larviciding must recommence to avoid proliferation of the savanna fly populations and prevent reinvasion of river systems in adjacent Guinea. In this area epidemiological data indicated onchocerciasis was of the forest form but this required confirmation by molecular identification. Present ATPs in north Sierra Leone are still consistent with onchocerciasis being a public health problem (an ATP greater than 100). The prevalence of infection, whilst still high, is lower than the pre-control level and similar to what was obtained before treatment was suspended. The strategy of intensive ivermectin distribution (twice yearly) and larviciding until 2002 is the only available strategy with continued community directed distribution post 2002 . The 2-4 year gap in larviciding in these key areas will require the OCP to be aware of the implications further east, as transmission by savanna flies, albeit at a lower level, has continued to introduce new infections in the population. This area would be an ideal region to introduce a macrofilaricide if it was available.

Area 3: Western extension

\section{Southern Sierra Leone}

In this area, high ATPs and CMFLs were found although the level of blindness observed and the severity of ocular morbidity was not compatible with parasitological findings or as severe as in classical savanna blinding onchocerciasis (Dadzie et al., 1992; De Sole et al., 1991, 1993). Studies on the vectors indicated the presence of a new Simulium species, $S$. leonense, which has a remarkably high vectorial capacity but transmits a less blinding form of $O$. volvulus (Boakye et al., 1993). Simulium leonense is a forest species with limited migratory capacity not seemingly capable of establishing itself outside its limited area of distribution of southern Sierra Leone and Liberia. The extensive and vast breeding sites used by $S$. leonense in rivers such as the Sewa with one of the highest discharges in West Africa would mean larviciding which, even if appropriate, would be extremely expensive and S. leonense in any case does not pose a threat to the original OCP area. Control is therefore only feasible by ivermectin which was begun in 1990 but suspended a year later due to the unstable security situation.
Area 4: Western extension

\section{Mali, southern Guinea}

This area of the upper Niger basin has been subjected to regular control by larviciding and annual ivermectin distribution in former hyper- and meso-endemic villages since 1987/1989. This combined approach will continue for a 12 year period. To date there has been a more rapid reduction in ocular morbidity indicators compared with the previous experience in core OCP areas when ivermectin was not available between 1974 and 1987, whilst larviciding in these river systems has arrested migration of Simulium into the western parts of the initial OCP area. There has been a rapid reduction of all epidemiological parameters (ATP, CMFL, prevalence) with no incidence in children under-5 born since control began and excluded from ivermectin treatment. Ophthalmological evaluation after 7 years of ivermectin treatment and larvicidal control showed reductions in both anterior segment (sclerosing keratitis $-37 \%$ reduction and iridocyclitis $-77.5 \%$ reduction) and posterior segment (optic nerve disease $-46 \%$ reduction) whilst the prevalence of microfilariae in the eye was reduced over a 7 year period from $21.6 \%$ to less than $1.7 \%$. The mean microfilarial load in the anterior chamber is of the order of $0.1 \%$.

\section{Area 5: Southern extension in Côte d'Ivoire}

This area has been subjected to larviciding in 1979 and regular ivermectin distribution since 1992 when it was recognized that savanna Simulium were breeding further south than expected. The area has also posed problems due to temephos insecticide resistance. In some zones outside the OCP area in Côte d'Ivoire, Lower Comoe and Lower Sassandra, deforestation has provided further opportunities for increased populations of savanna cytospecies to colonize river systems thereby increasing the capacity for transmission of savanna $O$. volvulus in an area where both forest and savanna forms of $O$. volvulus are present. This therefore makes the epidemiology complex, a situation which is further exacerbated by extensive patterns of human migration.

Area 6: South-east extension

\section{Benin, Togo, Ghana}

In this area, the control by larviciding and ivermectin distribution is scheduled for a 12 year period since the commencement of control in the late 1980s. Similar changes in the epidemiological patterns (incidence, CMFL, prevalence, ocular disease) have occurred to those in the western extension. There is some infiltration of infected flies from the eastern border where uncontrolled areas of Nigeria are reservoirs of infection. Any threat to the programme area is mitigated by continuous ivermectin distribution in eastern border areas of the Okpara/Oueme river systems and the Sota/Alibori river basin. As in southern areas of Côte d'Ivoire there are complex epidemiological patterns caused by a mix of several cytospecies transmitting both forest and savanna Onchocerca. In addition, in some areas, vector control is 
difficult due to mountainous conditions (Oti, Pendjari; Atacora regions) where many small streams act as breeding sites of both savanna flies and S. squamosum. These areas cannot be effectively treated using helicopters and the villages are difficult to access for ivermectin distribution because of the mountainous terrain.

\section{Area 7: Original programme area}

Throughout this area onchocerciasis is no longer a public health problem. The areas identified below are those subjected to special interventions to reduce any long term risk of recrudescence. These are identified on fig 2. as points $\mathrm{a}-\mathrm{f}$.

a Kankelaba, Mali. In this area, fly reinvasion from the west occurred until 1989 when the extension area became under effective control in Guinea. Larviciding and ivermectin treatment will continue until the epidemiological parameters are judged satisfactory.

b Dienkoa area of Burkina Faso (Upper Black Volta). An unrecognized breeding site maintained a focus of transmission during early phases of the OCP. Ivermectin distribution together with ground larviciding (using temephos and Bacillus thuringiensis H14 toxin) are currently maintained. The key indicator to assess effectiveness of control in this area is the incidence of infection.

c Bougouriba Basin, Burkina Faso. This area has been the subject of concern since 1995 when high prevalences were found in some villages which had shown an apparent rapid increase and spread of prevalence over a period of 12 months. Studies to ascertain the reason for and dynamics of this recrudescence are underway. The likely reasons are that unidentified breeding sites remained as sources of flies after exceptional hydrological conditions in the mid-1980s new breeding sites were created or that migration of infected individuals from outside the OCP occurred; this is unlikely as the settlement process was controlled by a national authority. The dynamics of recrudescence in this area, e.g. the extent of areas of high prevalence, the rate of spread and a comparison of the predicted dynamics of transmission on the basis of the ONCHOSIM model (Habbema et al., 1992; Plaisier, 1996), need to be compared with the observed changes in epidemiological parameters to understand not only the most appropriate modes of ivermectin delivery but also the frequency of treatment to reduce or arrest transmission.

d Kulpawn and Mole river systems, Ghana. In this region some villages maintain a relatively high prevalence (10-20\%) despite low CMFLs; some children have also been found infected, despite $15+$ years of vector control. A bi-annual distribution of ivermectin has been introduced in villages with high prevalences together with parallel epidemiological studies.

e South West Ghana/Black Volta. In areas around the major breeding sites of the Black Volta, transmission control has not been as effective as anticipated. However, in the area south of Bui in the Tano river system, south of the OCP border, epidemiological studies are underway to assess the prevalence of savanna onchocerciasis and the frequency of colonization of savanna blackflies in deforested areas in the Tano river f Sota-Alibori area of north Benin. The continuous infiltration of infected blackflies from Nigeria has allowed transmission to continue, so that distribution of ivermectin every 6 months must be maintained as a control measure.

As the OCP draws to a close it will need to closely monitor areas where continuing special interventions will be required using ivermectin distribution strategies especially in the Oti/Pendjari area; Pru basin, Ghana; Tinkissou basin in Guinea. Control beyond the year 2002 will be dependent upon the commitment of national resources and the efficacy of community-directed ivermectin treatment programmes.

\section{Acknowledgements}

Professor Molyneux is grateful for the early encouragement in his career from Donald Lee as well as the opportunity to publish this paper with colleagues in the Onchoceriasis Control Programme.

\section{References}

Boakye, D.A., Post, R.J., Mosha, F.W., Surtees, D.P. \& Baker, R.H.A. (1993) Cytotaxonomic revision of the Simulium sanctipauli subcomplex (Diptera: Simuliidae) in Guinea and the adjacent countries including description of the two new species. Bulletin of Entomological Research 83, 171-186.

Crosskey, R.W. (1987) A taxa summary for the Simulium damnosum complex, with special reference to distribution outside the control areas of West Africa. Annals of Tropical Medicine and Parasitology 81, 181-192.

Dadzie, K.Y., De Sole, G. \& Remme, J. (1992) Occular onchocerciasis and the intensity of infection in the community. IV. The degraded forest of Sierra Leone. Tropical Medicine and Parasitology 43, 75-79

De Sole, G., Baker, R., Dadzie, Y.D., Giese, J., Guillet, P., Keita, F.M. \& Remme, J. (1991) Onchocerciasis distribution and severity in five West African countries. Bulletin of the World Health Organization 69, 689-698.

De Sole, G., Accorsi, A., Creusvaux, H., Giese, J., Keita, F.M. \& Remme, J. (1993) Distribution of onchocerciasis in selected river basins of four West African countries. Tropical Medicine and Parasitology 44, 159-164.

Duke, D.O.L., Lewis, D.J. \& Moore, P.J. (1966) OnchocercaSimulium complexes I. Transmission of forest and Sudan savanna strains of Onchocerca volvulus from Cameroon by Simulium damnosum from various West African bioclimatic zones. Annals of Tropical Medicine and Parasitology 60, 318-336.

Garms, R., Walsh, J.F. \& Davies, J.B. (1979) Studies on the reinvasion of the Onchocerciasis Control Programme in the Volta River basin by Simulium damnosum s.l. with emphasis on the south western areas. Tropenmedizin und Parasitologie 30, 345-362.

Habbema, J.D.F., Alley, E.S., Plaisier, A.P., Van Oortmarssen, G.J. \& Remme, J.H.F. (1992) Epidemiological modelling for Onchocerciasis control. Parasitology Today 8, 99-103. 
Le Berre, R., Walsh, J.F., Phillipon, B., Poudiougo, P., Henderickx, J.E.E., Guillet, P., Seketeli, A., Quillévéré, D., Grunewald, J. \& Cheke, R.A. (1990) The Onchocerciasis Control Programme: retrospect and prospects. Philosophical Transactions of the Royal Society London B 328, 721-729.

Molyneux, D.H. (1995) Onchocerciasis control in West Africa: current status and future of the Onchocerciasis Control Programme. Parasitology Today 11, 399-402.

O-Now (1990) Proceedings of the Symposium on Onchocerciasis, Leiden, The Netherlands, $481 \mathrm{pp}$.

Plaisier, A.P. (1996) Modelling onchocerciasis transmission and control. 181 pp. PhD thesis, Erasmus University, Rotterdam.

Remme, J.H.F. (1995) The African Programme for Onchocerciasis Control: preparing to launch. Parasitology Today 11, 403-406

Samba, E.M. (1994) The Onchocerciasis Control Programme in West Africa. An example of effective public health management. $107 \mathrm{pp}$. WHO, Geneva.

Trees, A.J. (1992) Onchocerca ochengi: mimic, model or modulator of O. volvulus. Parasitology Today 8, 337-339.
Webbe, G. (1992) The Onchocerciasis Control Programme. Transactions of the Royal Society of Tropical Medicine and Hygiene 86, 113-114.

World Health Organization (1995) Onchocerciasis and its control. Report of a WHO Expert Committee Technical Report Series 852, $103 \mathrm{pp}$.

World Health Organization (1997) Twenty years of onchocerciasis control in West Africa. Review of the work the Onchocerciasis Control Programme in West Africa from 1974-1994. Published by the World Health Organization.

Zimmerman, P.A., Dadzie, Y.D., De Sole, G., Remme, J., Alley, E.S. \& Unnasch, T.R. (1992) Onchocerca volvulus DNA probe classification correlates with epidemiological patterns of blindess. Journal of Infectious Diseases 165, 964-968.

(Accepted 19 February 1997) (C) CAB INTERNATIONAL, 1997 